\title{
Definiëring in 'n aanleerderwoordeboek
}

\author{
A.E. Feinauer, Dept. Afrikaans en Nederlands, Universiteit van Stellenbosch
}

\begin{abstract}
Defining in a Learner's Dictionary. Because a learner's dictionary (in this case Basiswoordeboek oir Afrikaans) is directed at the foreign language user it stands to reason that the definitions therein will differ to a great extent from those used in a standard descriptive dictionary (for this article the Nasionale Woordeboek). This article discusses the differences in defining between these two types of dictionaries. The dissimilarity in the use of these dictionaries results in the main differences in defining: where the standard descriptive dictionary is used mainly for decoding, the learner's dictionary is used for decoding as well as encoding of text. Therefore the definiens should be as unambiguous and user-friendly as possible. The ways in which this could be achieved are described, such as the use of full sentences, basic vocabulary, etc.
\end{abstract}

Keywords: DEFINIENDUM, DEFINIENS, DEFINING, DEFINITION, DICTIONARY, GENUS DIFFERENTIA DEFINITION, LEARNER'S DICTIONARY, LEXICOGRAPHER, LEXICOGRAPHY, STANDARD DESCRIPTIVE DICTIONARY, SYNONYM DEFINITION, SYNTAX, VOCABULARY.

Opsomming: 'n Aanleerderwoordeboek (in hierdie geval die Basiswoordeboek vir Afrikaans) is gemik op die vreemdetaalgebruiker, en daarom is dit logies dat die definisies in so ' $n$ woordeboek grootliks sal verskil van dié wat in ' $n$ al gemene standaardwoordeboek (vir hierdie artikel die Nasionale Woordeboek) gebruik word. Hierdie artikel ondersoek die verskille in definiëring tussen hierdie twee tipes woordeboeke. Die verskil in die gebruik van hierdie woordeboeke gee aanleiding tot die belangrikste verskille in definiëring: waar die algemene standaardwoordeboek hoofsaaklik vir dekodering gebruik word, word die aanleerderwoordeboek vir sowel dekodering as enkodering van teks gebruik. As gevolg hiervan word vereis dat die definiens in 'n aanleerderwoordeboek so ondubbelsinnig en gebruikervriendelik as moontlik moet wees. Die onderskeie wyses waarop die definisie so toeganklik gemaak word, word beskryf, byvoorbeeld die gebruik van volsinne, kernwoordeskat, ens.

Sleutelwoorde: DEFINIENDUM, DEFINIENS, DEFINIëRING, DEFINISIE, WOORDEBOEK, GENUS-DIFFERENTIA-DEFINISIE, AANLEERDERWOORDEBOEK, LEKSIKOGRAAF, LEKSIKOGRAFIE, ALGEMENE STANDAARDWOORDEBOEK, SINONIEMDEFINISIE, SINTAKSIS, WOORDESKAT

\section{Inleiding}

'n Aanleerderwoordeboek is gerig op die niemoedertaalspreker. Die teorie oor 
aanleerderwoordeboeke, en dan spesifiek dié oor definiëring in aanleerderwoordeboeke, is al deeglik in die internasionale leksikografie beskryf. Binnelands het Otto (1989) 'n omvattende studie gedoen oor die teoretiese sowel as die praktiese eise waaraan 'n aanleerderwoordeboek vir Afrikaans moet voldoen. Hierdie artikel gaan meer prakties van aard wees, en dit gaan kyk hoe lyk 'n definisie in 'n aanleerderwoordeboek (spesifiek die Basiswoordeboek vir Afrikaans), en hoe verskil dit van die definisies in ons algemene standaardwoordeboeke (vir die doeleindes van hierdie artikel die Nasionale Woordeboek).

\section{Aard van definisie}

Die belangrikste verskille tussen die definisies van die Basiswoordeboek vir Afrikaans (BVA) en dié van Nasionale Woordeboek (NW) spruit uit die verskil in die gebruik van die twee woordeboeke. Die NW word hoofsaaklik vir die dekodering van teks gebruik, terwyl BVA vir sowel dekodering as enkodering van teks gebruik word. Dit lei dan daartoe dat die meeste BVA-definisies tweeledig is: die eerste deel dui gebruik aan, terwyl die tweede deel die betekenis verduidelik. Die grootste verskil tussen die woordeboeke se definisies lê daarin dat BVA 'n veel uitgebreider definisie het as NW.

Die uitgebreidheid van die BVA-definisie is ook die gevolg daarvan dat die gebruiks- en betekenisinligting op so 'n manier aangebied word dat daar geensins ' $n$ beroep op die taalintuïsie van die gebruiker gedoen word nie. Dit doen wel deeglik 'n beroep op die leksikografiese vaardigheid van die skrywer as moedertaalspreker.

Watter eise word dan aan die leksikograaf gestel? Hy moet sorg dat sy definiens verstaanbaar en akkuraat is. Volgens Rundell (1988: 127) moet sy produk so toeganklik en gebruikervriendelik as moontlik wees.

\section{$2.1 \quad$ Woordeskat}

Om dit so verstaanbaar moontlik te maak, word die beskrywing in groter detail as in NW gedoen, maar alhoewel die definisie langer is, het die leksikograaf minder woorde om mee te definieer (Kirkpatrick 1985: 10). Die rede hiervoor is dat alle woorde wat in ' $n$ definiens gebruik word, elders in die woordeboek verklaar moet word. Indien die gebruiker dus nie ' $n$ woord in 'n definiens verstaan nie, moet hy hierdie woord kan naslaan. Dieselfde beginsel geld vir gewone algemene standaardwoordeboeke, maar wat in ag geneem moet word, is dat ' $n$ gekontroleerde woordeskat in 'n aanleerderwoordeboek as definienda opgeneem word; net dit wat die leksikograaf as kernwoordeskat beskou, word gebruik (Underhill 1985: 104). Dit lei dan amper noodwendig daartoe dat die definiens nie woorde sal bevat wat moeiliker is om te verstaan as die definiendum nie. Hierdie definiëringsfout kom wel in NW voor waar in voorbeelde (1) 
en (2) sowel gewelf as uurwerk moeiliker en vreemder begrippe as onderskeidelik verhemelte en oorlosie is.

(1) VERHEMELTE "gewelf van die mond, monddak" (NW) "'n Mens se verhemelte is die boonste gedeelte van die binnekant van jou mond." (BVA)

(2) OORLOSIE "uurwerk" (NW)

"'n Oorlosie is iets waarop 'n mens kyk om te sien hoe laat dit is." (BVA)

Die leksikograaf moet ook sorg dat die woorde wat in 'n definiens gebruik word, ondubbelsinnig is in terme van die konteks. As 'n dubbelsinnige woord gebruik word, moet die regte betekenisonderskeiding duidelik uit die res van die definiens blyk (Otto 1989: 190). In die BVA is dit nie so 'n probleem soos in byvoorbeeld die NW nie, want die gebruik van volsinne help om dubbelsinnigheid tot 'n groot mate uit te skakel.

(3) FLATER "misslag, blaps, bok" (NW)

"Wanneer 'n mens ' $n$ flater begaan, maak jy 'n dom of agtelosige fout" (BVA)

Let op die tipiese 'n flater begaan wat as voorbeeldsin in NW gegee word, en waaruit die oningeligte gebruiker niks meer wys word nie. In BVA is die kollokasie flater begaan deel van die definisie, en dan volg die voorbeeldsinne eers: "Hy het 'n groot flater begaan toe hy haar voor haar kêrel fliek toe genooi het".

Vroeër is genoem dat daar nie ' $n$ beroep op die intuïsie van die gebruiker gedoen kan word nie. Daarom moet idiome en metafore nie as deel van die definiens opgeneem word nie, want dis meestal ondeursigtig vir niemoedertaalsprekers (Otto 1989: 195).

(4) VERSIGTIG "1. op jou hoede; wat rekening hou met gevare; behoedsaam. 3. bedag." (NW)

"Wanneer iemand versigtig is, dink hy goed voordat of terwyl hy iets doen, en hy doen dit noukeurig sodat hy nie 'n fout of 'n ongeluk maak nie:" (BVA)

(5) VERSPREI "wat hier en daar, op verskillende plekke, ver uitmekaar (en yl) staan of voorkom." (NW)

"lets wat versprei is, kom ver uitmekaar op verskillende plekke voor." (BVA)

Die leksikograaf moet bedag wees op hierdie idiomatiese tipe taalgebruik in sy definiëring, want as moedertaalspreker voel hy dit nie meer aan as idiomaties 
of metafories nie. Die definiendum vasbeslote is eers as volg beskryf:

(6) VASBESLOTE "Iemand wat vasbeslote is om iets te doen, gaan nie maklik sy besluit laat vaar/afsien van sy besluit nie".

Die minder idiomatiese variant wat nou opgeneem is, lui:

"Iemand wat vasbeslote is om iets te doen, gaan nie maklik sy besluit verander om dit nie te doen nie".

Fabriek se definiens lui op die oomblik:

(7) FABRIEK "'n Fabriek is 'n groot gebou of 'n groep geboue waar goedere op groot skaal gemaak word."

Die op groot skaal sal vervang moet word met byvoorbeeld in groot hoeveelhede.

\subsection{Sintaksis}

Dit wat seker die meeste verskil tussen die definiense van die algemene standaardwoordeboek en dié van aanleerderwoordeboeke is dat aanleerderwoordeboeke volsinne as definiense gebruik. Afgesien van die groter verstaanbaarheid wat daaruit spruit - onder andere die uitskakeling van dubbelsinnigheid, want die betekenis word in konteks verklaar - is nog 'n voordeel dat natuurlike taalgebruik gewaarborg word. Die definiense in BVA is volgens die patroon van Collins COBUILD English Language Dictionary (COB) waar die definiense ontwerp is om soos gewone Engels te lees. Die lemma word op so ' $n$ manier in die verklaring genoem dat ' $n$ mens kan sien hoe dit tipies in Engels gebruik word. In die meeste gevalle verskaf die definiens 'n illustrasie van die woord in sy tipiese grammatikale konteks (Otto 1989: 207). Vergelyk Cowie (1987: 187): "Context focuses or colours the meaning to a varying degree. We cannot separate a word from its context, nor would it be desirable to do so."

Die tipiese COB-definiens, en so ook die BVA-definiens, kan in twee dele verdeel word.

\subsubsection{Eerste deel van definiens}

Die eerste deel van die definiens is dit wat die meeste van dié in die gewone algemene standaardwoordeboek verskil. Hier word die definiendum in sy mees tipiese sintaktiese optrede en plasing aangetref sodat as die tweede deel van die definiens nie helder genoeg is nie, die eerste deel moet help om die 
betekenis uit te bring (Underhill 1985: 104 en 105). Oor die algemeen dui die eerste deel van die definiens gebruik aan, terwyl die tweede deel die betekenis verduidelik; die eerste deel help die gebruiker om te enkodeer, terwyl die tweede deel vir dekodering gebruik word (Otto 1989: 210).

Hoe lyk so ' $n$ verklaring van ' $n$ bepaalde definiendum in sy tipiese grammatikale konteks, en wat kry die aanleerder bykomend?

Eerstens wat naamwoorde betref:

(8) VALSKERM "'n Valskerm is 'n toestel waarmee 'n mens uit 'n vliegtuig kan spring, en dan veilig op die grond kan land." (BVA) "sambreelagtige toestel waarmee mens uit 'n vliegtuig spring." (NW)

(9) REëN "Reën is water wat in druppels uit die wolke kom." (BVA) "neerslag van water uit die lug." (NW)

Bloot deur die aan- of afwesigheid van lidwoorde weet die gebruiker of hy met ' $n$ tipiese soortnaamwoord of massanaamwoord te doen het.

'n Naamwoord wat uniek is aan mense word so beskryf dat dit uit die definiens blyk:

(10) VAN "'n Mens se van is die naam wat jy met die res van jou gesin of familie deel. Dit staan gewoonlik na jou noemnaam." (BVA) "familienaam." (NW)

Naamwoorde wat metafories gebruik word, se definiense verskil van dié wat konjunk gebruik word:

(11) VARK "1. 'n Vark is 'n soogdier met kort beentjies, 'n ronde snoet en 'n krulstert wat hoofsaaklik vir sy vleis geteel word.

2. Iemand wat baie onaangenaam is of hom baie swak gedra, kan 'n vark genoem word." (BVA)

"1. soogdier met gesplete hoewe geteel vir vleis en spek.

2. liederlike mens." (NW)

Wat heelwat duideliker uit BVA se definiens blyk, is die spreker se bedoeling om iemand te beledig. Die betekenis van vark 2 is nie so belangrik as eerder vir wie of wanneer dit gebruik word nie. Let ook daarop dat die definiens nie begin soos by vark 1 met " $n$ Vark is 'n mens wat hom ..." nie. Die aanleerder kan dit te maklik as 'n konjunkte gebruik van vark interpreteer of anders kan hy die metaforiese vark as topiek in die tipiese onderwerpposisie saam met ' $n$ onbepaalde lidwoord laat optree. Metaforiese woorde tree nie in natuurlike taal so op nie: "' $n$ Vark het nou net by die deur ingestap" of "Daar het nou net 'n vark by die deur ingestap". Dit is wel 'n tipiese sintaktiese posisie vir die konjunk gebruikte naamwoord. Vergelyk verder Hanks (1987: 134). Vaste uit- 
drukkings word ook so gedefinieer dat die eerste deel van die definiens klem lê op die situasie waar of wanneer dit gebruik word.

(12) DIT REëN KATTE EN HONDE "Wanneer 'n mens sê dit reën katte en honde, beteken dit dit reën baie hard." (BVA)

Wat die definiëring van werkwoorde betref, kan die aanleerder onmiddellik sien of hulle oorganklik, onoorganklik, of as albei gebruik kan word, terwyl hierdie inligting dikwels uit die voorbeeldsinne in algemene standaardwoordeboeke afgelei moet word.

(13) RAADPLEEG "Wanneer ' $n$ mens iemand of iets raadpleeg, vra jy raad, hulp of inligting by hom of dit." (BVA)

"1. raad vra, inwin by." (NW)

Uit hierdie definiens kan die gebruiker verskeie dinge aflei: eerstens word raadpleeg oorganklik gebruik, die onderwerp is gewoonlik menslik, maar die voorwerp kan menslik of niemenslik wees.

(14) OMDRAAI "Wanneer 'n mens iets omdraai, beweeg jy dit in 'n ander rigting; die bokant is nou byvoorbeeld onder, of die voorkant is nou agter. Wanneer 'n mens omdraai, beweeg jy in ' $n$ ander rigting." (BVA)

"1. andersom plaas; omkeer. 2. teruggaan, terugkeer. 3. van een kant na die ander draai." (NW)

Uit die BVA-definiens sien die gebruiker dat omdraai sowel oorganklik as onoorganklik gebruik kan word; in albei gevalle is die onderwerp gewoonlik menslik, maar die voorwerp is meestal niemenslik.

In die volsindefiniens word die setsel ook aangetref wat saam met die werkwoord optree, terwyl dit in die NW eers in die voorbeeldsin blyk:

(15) HEERS "Wanneer 'n mens oor iemand of iets heers, het jy die mag om te beheer wat hy of dit doen, en jy gebruik dan hierdie mag." (BVA)

"1. gesag uitoefen; heerskappy voer. 2. die oorhand hê; jou mag sterk laat geld." (NW)

Wanneer die werkwoord gewoonlik met 'n spesifieke voorwerp verbind, word die voorwerp eksplisiet genoem, en nie vervang deur iemand of iets nie.

(16) VERAS "Wanneer 'n lyk veras word, word dit verbrand." (BVA) "verbrand, kremeer." (NW) 
Uit BVA se definiens kan onmiddellik gesien word dis 'n lyk wat veras word, terwyl dit volgens NW kan dui op enigiets wat verbrand word; die voorbeeldsin in NW sê wel 'n Lyk -. Die meeste werkwoorde wat in BVA opgeneem is, is tot menslike onderwerpe beperk; ook veras. Dit is egter nie 'n natuurlike handeling vir enige mens om lyke te veras nie, en daarom word die passiewe opsie gebruik in plaas van die algemener "Wanneer 'n mens 'n lyk veras..."

Volgens Hanks (1987: 126) kan dieselfde neutraliteit ten opsigte van die doener verkry word deur ' $r$ infinitiefkonstruksie te gebruik; sodoende word die doener net soos by die kort passief verswyg. Dit geskied veral by werkwoorde wat onwettige of onsedelike handelinge aandui. Vergelyk:

(17) VERMOOR "Om iemand te vermoor, beteken om hom opsetlik dood te maak." (BVA)

"opsetlik doodmaak, gewelddadig om die lewe bring." (NW)

Sou die leksikograaf hier die definiens inlui met 'Wanneer ' $n$ mens iemand vermoor ..." mag dit vir die gebruiker impliseer dat dit natuurlik is om iemand te vermoor. Wanneer die fokus verskuif word, en die definiens lui: "Wanneer iemand jou vermoor ..." kan die gebruiker dalk ontstel word, terwyl die neutraler "Wanneer iemand iemand vermoor ..." weer voornaamwoordelike verwysingsprobleme kan oplewer. Daarom dan eerder die infinitief.

Die infinitief word ook gebruik by die beskrywing van baie algemene werkwoorde waar dit eintlik geen doel dien om 'n doener te noem nie:

(18) OORTREK "Om iets oor te trek, beteken om dit van een kant na 'n ander te trek." (BVA)

"2. van een plek na 'n ander trek." (NW)

Terloops, NW behandel oortrek 2 en die oortrek wat beteken "om iets met iets anders te bedek" as poliseme, terwyl hulle in BVA as homonieme aangebied word.

Wat die definiense van adjektiewe betref: die oorgrote meerderheid kan predikatief en attributief gebruik word. Hier word die definiense gewoonlik soos volg aangebied:

(19) OULIK "Iets of iemand wat oulik is, is mooi, aantreklik, of 'n mens hou daarvan of van hom." (BVA)

"aantreklik, mooi." (NW)

By 'n adjektief soos onderhewig aan kan 'n mens nie eintlik uit die definiens aflei dat dit uitsluitlik predikatief optree nie, maar dan word dit onder die hofie opmerkings genoem. Adjektiewe wat net attributief optree, sou as volg in BVA geakkommodeer kon word: "Die/'n onderkantste iets is iets wat aan die onderkant is." Die definiens lees egter nie natuurlik nie. Die probleem is 
soos volg uit die weg geruim:

(20) ONDERKANTS(T)E "Wanneer 'n mens verwys na die onderkantste ding, verwys jy na iets wat aan die onderkant is." (BVA) "wat aan die onderkant is." (NW)

Saam met hierdie definiens is daar ook 'n opmerking dat onderkantste net attributief gebruik word.

Volgens Otto (1989: 181) benodig funksiewoorde soos voegwoorde, neweskikkers, lid woorde en voorsetsels funksionele definisies; dit wil sê dié definisietipe waarin die funksie van die betrokke woord beskryf word. Die belangrikste aspek by die definiense van funksiewoorde in aanleerderwoordeboeke is nie soseer om hulle betekenisse weer te gee nie, maar eerder om korrek en uitvoerig aan te dui hoe hulle gebruik word. Dat gebruik en nie betekenis nie hier sentraal staan, blyk reeds uit die eerste deel van die definiens:

(21) OF (newesk.) "1. Of word gebruik om 'n aantal keuses of alternatiewe aan mekaar te las." (BVA)

"ter verbinding van twee sinne of sinsdele wat mekaar uitsluit." (NW)

OF (ondersk.) "Of word aan die begin van 'n bysin gebruik waar 'n mens nie seker is oor die inhoud van die bysin nie." (BVA) "grammaties verbindende voegw. in bysinne waarvan die inhoud as twy felagtig beskou word." (NW)

(22) VAN (sts.) "1. Van word gebruik om besit aan te dui; die vensters van die huis dui daarop dat die vensters aan die huis behoort.

2. Van word gebruik om ' $n$ beginpunt of plek van oorsprong aan te dui.

4. Van dui oorsaak of rede aan. (bleek van woede)" (BVA)

"1. ter aanduiding van besit of bron.

2. uit; afkomstig van." (NW)

Wat veral by funksiewoorde belangrik is, is dat daar baie voorbeeldsinne gegee moet word sodat die gebruik in feitlik elke moontlike konteks geillustreer word.

\subsubsection{Tweede deel van definiens}

Die tweede deel van die definiens in 'n aanleerderwoordeboek lyk meer na die tradisionele definiens in die algemene standaardwoordeboek, want hier vind die eintlike identifisering van betekenis plaas. Die leksikograaf moet egter sorg 
dat hy hier net dit noem wat tipies so is; hy moet dus die normale patroon beskryf, wat nie altyd noodwendig is nie (Hanks 1987: 118). Die tipiese is vir die aanleerder baie belangriker as die moontlike, want op sy vlak van taalgebruik gaan hy baie eerder met die tipiese gekonfronteer word. Die aanbieding van die tipiese moet so gedoen word dat dit nie die moontlike uitsluit nie.

(23) OOND "'n Oond is 'n toe ruimte gewoonlik met 'n deur aan waarin iets gebak word." (BVA)

"toe ruimte om in te bak, smelt, ens. teen 'n hoë temperatuur." (NW)

Die mees tipiese gebruik vir 'n oond word genoem alhoewel 'n oond ook gebruik sou kon word om byvoorbeeld iets droog te maak, of om iets te ontdooi, ensovoorts.

Ook wat betref die polisemiese waardes van die definienda, word net die mees tipiese betekenisonderskeidings uitgesonder om opgeneem te word. By die lemma huis sal die leksikograaf byvoorbeeld nie die volgende betekenisonderskeidings opneem nie: "3. gebou vir 'n bepaalde doel gebruik; 4. handelshuis, firma; 6. wetgewende liggaam, kamer" (NW). In BVA is net twee betekenisonderskeidings vir huis opgeneem, naamlik "'n gebou waarin mense woon" en "tuiste".

Omdat die gebruiker van die aanleerderwoordeboek geen taalintuïsie het nie, word die definiens soos reeds genoem in veel groter detail gedoen as dié in die algemene standaardwoordeboek. Dit het die voordeel dat die aanleerderdefiniens soms akkurater en vollediger is, en die definiendum sodoende uniek onderskei word van die ander lede in sy klas, maar aan die ander kant lei dit ook daartoe dat daar 'n groter mate van saakbeskrywing in 'n aanleerderwoordeboek aanwesig is. Veral by name vir plante en diere is die algemene standaardwoordeboeke soms geneig om te min onderskeidende eienskappe aan te dui. Vergelyk:

(24) NARTJIE "'n Nartjie is 'n sitrusvrug, en dit lyk amper soos 'n klein lemoentjie, maar dit het 'n los, dun skil." (BVA) "geurige sitrusvrug met 'n los, dun skil." (NW)

(25) HAAS '"n Haas is 'n kleinerige diertjie (omtrent so groot soos 'n kat) met 'n sagte pels, lang ore, en 'n kort stertjie." (BVA)

"kleinerige knaagdier met lang ore wat vinnig kan hardloop." (NW)

Akkurater saakbeskrywing word ook aangetref ter wille van beter onderskeiding by:

(26) HOMP "'n Homp is 'n groot dik stuk gewoonlik van iets wat 'n mens eet." (BVA)

"groot dik stuk wat van iets afgesny of afgebreek is." (NW) 
Dat homp hoofsaaklik met kos te make het, moet in NW uit die voorbeeldsinne afgelei word terwyl dit baie meer deel van sy betekenis is, as dat dit afgesny of afgebreek is. Net so kan daar nie uit die standaardwoordeboek afgelei word wat die verskil tussen byvoorbeeld 'n omelet en roereier is nie. In BVA word saakbeskrywing ter wille van 'n akkurater onderskeid gebruik.

(27) OMELET "'n Omelet is'n gereg wat van geklitste eiers gemaak word, en soos 'n pannekoek in 'n pan gebak word." (BVA) "geklitste, gebakte eiergereg." (NW)

(28) ROEREIER(S) "Roereiers is 'n gereg wat bestaan uit eiers wat in 'n pan geroer word terwyl dit gaar word." (BVA)

"gereg bestaande uit eier met melk geklits en gaar gemaak." (NW)

Veral by deiktiese woorde word heelwat uitvoeriger definiense aangetref as by die standaardwoordeboek. Hier is daar nie eintlik sprake van meer saakbeskrywing nie, maar eerder van die aanduiding van al die betekenismomente wat byvoorbeeld in ' $n$ deiktiese werkwoord soos haal is. Wat die beskrywing van deiktiese werkwoorde betref, skiet ons standaardwoordeboeke nog ver tekort.

(29) HAAL "1. Wanneer 'n mens iemand of iets gaan/kom/loop haal, bring jy dit van 'n bepaalde plek deurdat jy soontoe gaan om dit te kry." (BVA)

"1. gaan of kom en saamneem." (NW)

\section{Definisietipe}

Die algemeenste tipe definisie wat in BVA gebruik word, is die analitiese definisie waarin die genus en differentia van die definiendum aangedui word. Die definiendum word eerstens deur middel van ' $n$ superordinaat binne ' $n$ bepaalde semantiese klas of genus geplaas waarna die verskille of differentia tussen die definiendum en die res van die lede in daardie genus aangedui word. Hierdie genus-differentia-definiëring kom net so algemeen in die standaardwoordeboeke voor.

(30) RADIO "'n Radio is ${ }_{g}[\text { 'n toestel }]_{g}$ [ [waarop 'n mens na programme kan luister wat uitgesaai word $]_{d} . "$ (BVA)

"3. ontvangstoestel vir radioprogramme; radiostel; draadloos." (NW) 
(31) NEUT "'n Neut is ' $n_{d}[\text { kleinerige harde }]_{d g}[v r u g]_{g d}[$ met 'n baie harde dop] $]_{\text {." (BVA) }}$

"eensadige vrug met 'n houterige of leeragtige wand wat nie oopspring nie." (NW)

Volgens Otto (1989: 237) behoort sinoniemdefinisies nie in 'n aanleerderwoordeboek opgeneem te word nie, want hulle kan misleidend wees. Sinonieme kan wel naas of saam met die definisie optree. Vergelyk byvoorbeeld die hantering van die lemmas verslag en rapport in NW:

(32) VERSLAG "(saaklike) berig, rapport, corsig (oor 'n gebeurtenis, toestand) (NW)

RAPPORT "1. verslag. 2, verslag van vordering met 'n lys van syfers." (NW)

Hierdie tipe sinoniemdefiniëring sal beslis nie in ' $n$ aanleerderwoordeboek slaag nie. Wat hierdie lemmas betref, slaag dit ook nie in 'n standaardwoordeboek nie, want nêrens kry die gebruiker die betekenis van óf rapport óf verslag nie, terwyl hy ook mislei word deur die twee betekenisonderskeidings by rapport. In BVA lyk die definiëring van verslag en rapport so:

(33) VERSLAG '"n Verslag is 'n formele of amptelike dokument waarin weergegee word byvoorbeeld die vordering van iets of iemand, of wat gesê of besluit is; rapport." (BVA)

RAPPORT "'n Rapport is 'n verslag veral oor die vordering van iemand of iets."

Hieruit kan die gebruiker dan aflei dat 'n rapport 'n tipe verslag is, maar hy sien dan ook presies wat ' $n$ verslag is. Rapport kan dus nie in alle gevalle as sinoniem vir verslag optree nie. Verslag word nie onder rapport as sinoniem gelys nie omdat dit as genus genoem word waaronder rapport ressorteer.

Alhoewel sinoniemdefiniense nie altyd akkuraat genoeg is nie, en hulle soms sake vir die gebruiker kan bemoeilik, is daar geen rede waarom dit nie in die aanleerderwoordeboek gebruik kan word nie mits die sinoniemdefinisie korrek gehanteer word. Vergelyk byvoorbeeld die hantering van die lemmas verniel, verrinneweer en rinneweer in BVA teenoor dié in NW:

(34) VERNIEL "Wanneer 'n mens iets verniel, breek of beskadig jy dit; (ver)rinneweer." (BVA)

VERRINNEWEER "Verniel, rinneweer." (BVA)

RINNEWEER "Verniel, verrinneweer." (BVA) 
VERNIEL "1. met geweld stukkend maak, verwoes." (NW) VERRINNEWEER "beskadig deur ru gebruik, vemiel." (NW) RINNEWEER "deur slegte of ru behandeling bederf, verniel." (NW)

Alhoewel BVA in hierdie geval meer van sinoniemdefiniëring gebruik maak as NW, is BVA se hantering van die onderskeie lemmas leksikografies meer korrek, en die betekenisverhouding tussen die drie lemmas word beter verklaar en aangetoon.

\section{Slotwoord}

Om in ' $n$ paar woorde saam te vat waarna die leksikograaf van 'n aanleerderwoordeboek moet streef: hy moet sy definiense so gebruikervriendelik moontlik maak, maar met die korrekte leksikografiese praktyk en taalkundige leiding.

\section{Aantekening}

- Die Basiswoordeboek oir Afrikaans (Hoofred. R.H. Gouws) is die eerste Afrikaanse eentalige aanleerderwoordeboek en sal eersdaags by Van Schaik verskyn.

\section{Verwysings}

Cowie, A.P. (Red.). 1987. The Dictionary and the Language Learner. Tübingen: Max Niemeyer.

Cowie, A.P. 1987. Syntax, the Dictionary and the Learner's Communicative Needs. Cowie, A.P. (Red.). 1987: 183-192.

De Villiers, M. e.a. 19877. Nasionale Woordeboek. Kaapstad: Nasou.

Hanks, P. 1987. Definitions and Explanations. Sinclair, J.M. (Red.). 1987: 116-136.

Ilson, R. (Red.). 1985. Dictionaries, Lexicography and Language Learning. Oxford: Pergamon Press.

Kirkpatrick. B. 1985. A Lexicographical Dilemma: Monolingual Dictionaries for the Native Speaker and for the Learner. Ison, R. (Red.). 1985: 7-13.

Otto, A.N. 1989. Kriteria vir 'n Afrikanse aamleerderwoordeboek. Ongepubliseerde D.Litt.-verhandeling. Universiteit van Stellenbosch.

Rundell, M. 1988. Changing the Rules: Why the Monolingual Learner's Dictionary Should Move A way from the Native-speaker Tradition. Snell-Hornby, M. (Red.). 1988: 127-137.

Sinclair, J. e.a. 19882. Collins COBUILD English Language Dictionary. Londen: Collins.

Sinclair, J.M. (Red.). 1987. Lonking Up. Londen: Collins.

Snell-Hornby, M. (Red.). 1988. ZulriLEX' 86 Proceedings: Papers read at the EURALEX Intemational Congress, University of Zürich, 9-14 September 1986. Tübingen: Francke Verlag.

Underhill, A. 1985. Working with the Monolingual Learners' Dictionary. Ilson, R. (Red.). 1985: $100-114$. 